\title{
Closure of the Trans-Columellar Incision in Open Rhinoplasty: Absorbable or Nonabsorable Suture?
}

\author{
Shayan Alijanpour ${ }^{1,2}$, Moslem Armoeyan ${ }^{3 *}$ and Parinaz Shahroudi ${ }^{3}$ \\ ${ }^{1}$ MSc student of Critical Care Nursing, Student Research Committee, Faculty of Nursing and Midwifery, Iran \\ ${ }^{2}$ Education, Research and Planning, Prehospital Emergency Organization and Emergency Medical Service Centre, Iran
}

${ }^{3}$ MSc student of Surgical Technology, Student Research Committee, Faculty of Nursing and Midwifery, Iran

*Corresponding author: Moslem Armoeyan, MSc student of Surgical Technology, Student Research Committee, Faculty of Nursing and Midwifery, Isfahan, Iran

\begin{abstract}
ARTICLE INFO
Received: 慧 August 25, 2019

Published: August 30, 2019

Citation: Shayan A, Moslem A, Parinaz S. Closure of the Trans-Columellar Incision in Open Rhinoplasty: Absorbable or Nonabsorable Suture? Biomed J Sci \& Tech Res 21(1)-2019. BJSTR. MS.ID.003540.
\end{abstract}

Abbreviations: PP: Polypropylene; VAS: Visual Analog Scale; SBSES: Stony Brook Scar Evaluation Scale; PGA: Polygalactic Acid

\section{ABSTRACT}

Objective: Open rhinoplasty is common technique because of easy and good access to the nasal building. However, the technique varies from surgeon to surgeon and according to which suture material is used to closure the Columella cut regarding beautifully and scar. Good scar results are important for patient satisfaction. Absorbable and non-absorbable suture materials are used in surgical wound closure.

Method: This study was conducted with key words that include of rhinoplasty, cosmetic techniques, wound closure techniques in data bases such as google scholar, web of sciences, pubmed, embase, sciencedirect between 2014 to 2019. Inclusion criteria include of Primary rhinoplasty with Inverted-V incision, English language study and Suture is performed by one surgeon. 15 study was included, and two authors read abstract carefully and if study not compared two methods use of absorbable and nonabsorbable suture in Transcolumellar incision were excluded. Finally, three articles were selected for this research. Informed consent not recommended in review article.

Conclusion: Results did not show the difference between the use of absorbable or nonabsorbable suture in terms of the scar but the use of absorbable suture for the patient and surgeon can be effective in terms of comfort, anxiety and working hours for removal it (respectively).

Keywords: Rhinoplasty; Cosmetic Technique; Wound Closure Technique

\section{Introduction}

Open rhinoplasty is common technique because of easy and good access to the nasal building. However, the technique varies from surgeon to surgeon and according to which suture material is used to closure the Columella cut regarding beautifully and scar [1-5]. Good scar results are important for patient satisfaction [6]. Absorbable and non-absorbable suture materials are used in surgical wound closure [7-8]. Regularly, non-absorbable sutures have been recommended for good aesthetic results, their minimal tissue reaction and protection of the knot tension. However, they should be removed at one week postoperative. removal nonabsorbable suture may traumatize the patient and can time consuming for the surgeon regarding postoperative following period, but Absorbable sutures do not require removal, therefore, can reduce anxiety of patient postoperatively [9-12]. The study was aimed at evaluation absorbable and non-absorbable sutures in closure trans columellar incision regarding patient discomfort, scarring and the risk for postoperative infection.

\section{Method}

This study was conducted with key words that include of rhinoplasty, cosmetic techniques, wound closure techniques in data bases such as google scholar, web of sciences, pubmed, embase, sciencedirect between 2014 to 2019. Inclusion criteria include of Primary rhinoplasty with Inverted-V incision, English language study and Suture is performed by one surgeon. 15 study was included, and two authors read abstract carefully and if study not compared two methods use of absorbable and non-absorbable 
suture in Trans columellar incision were excluded. Finally, three articles were selected for this research. Informed consent not recommended in review article.

\section{Results}

In Babak Alinasab et al. study, which was performed in Sweden in 2015, incision suture was done in 21 patients with non-resorbable suture material polypropylene (PP) (Prolene 5/0; Ethicon Inc.) and in 20 people with rapidly resorbable suture material, the $5 / 0$ irradiated Polygalactic acid (PGA); (Vicryl Rapide 5/0; Ethicon Inc.). In this study, evaluation the patient's Discomfort from the suture removal of the PP sutures was compared to trimming of the PGA sutures after one week postoperatively and assess the scar was done with a self-report questionnaire by the patient at least 6 months (Average 24 months for Prolene and 11 months for Vicryl) and evaluation of photo by 20 Rhinoplasty surgeon after the operation. The Trimming of absorbable than the non-absorbable suture significantly reduced the patient's discomfort $(\mathrm{p} \leq 0.01)$. There was no difference between the two groups regarding scar and the risk of infection. 17/21 (81\%) of the patients sutured with PP and 18/20 (90\%) of the patients sutured with PGA considered their scars to be invisible or almost invisible. The corresponding assessments from the observers were 16/21 (76 \%) and 16/20 (80\%), respectively [6]. In Nadia Ashraf et al. study, which was performed in London, Transcolumellar incision suture was done in 50 patients with Polypropylene 6/0 (Prolene $囚$, Ethicon Inc.) and 50 patients with (Vicryl Rapide ${ }^{\circledR}$; Ethicon Inc.).

The first group suture was removed after 1 week. After 3 months, Photo of patients was taken. Two surgeons with The Stony Brook Scar Assessment Scale evaluated photos. The mean score in the absorbable group was 3.45 and the non-absorbable group was 3.52 , but no significant difference was observed ( $p=0.39$ ). Dissatisfaction, infection and other complications were not reported. Although, in terms of scar there was no difference in two groups, but with absorbable suture, patients were more comfortable [11]. In Ahmet Erdem Kilavuz et al. study, which was done in Turkey since 20152016, 89 patients participated; the first group included 47 patients and 42 patients in the second group. The first group was sutured with absorbable polyglactin 910 (PG) (Vicryl Rapide 6/0; Ethicon Inc.) and the second group with non-absorbable polypropylene (PP) (Prolene 6/0; Ethicon Inc.). The evaluation was carried out on the 6th month with visual analog scale (VAS) and the modified Stony Brook Scar Evaluation Scale (SBSES). The scores of VAS for the first group was $8.04 \pm 0.91$ and the second group was $7.71 \pm 0.85$, and the scores of SBSES for Vicryl was $3.88 \pm 0.80$ and for Prolene was $3.67 \pm 0.80$. There were no significant differences in either of the two scales ( $\mathrm{p}=0.2$ and $\mathrm{p}=0.35$ respectively). Suture with Vicryl caused less patient anxiety and patient comfort and shorter working hours for surgeons to removal them [12].

\section{Conclusion}

The review of the studies did not show the difference between the use of absorbable or nonabsorable suture in terms of the scar but the use of absorbable suture for the patient and surgeon can be effective in terms of comfort, anxiety and working hours for removal it (respectively).

\section{References}

1. Cafferty A, Becker DG (2016) Open and closed rhinoplasty. Clinics in plastic surgery 43(1): 17-27.

2. Adamson PA, Constantinides M, Kim AJ, Pearlman S (2014) Rhinoplasty: panel discussion. Facial Plastic Surgery Clinics 22(1): 25-55.

3. Ors S, Ozkose M, Ors S (2015) Comparison of various rhinoplasty techniques and long-term results. Aesthetic plastic surgery 39(4): 465473.

4. Rojdmark J, Mouchammed A (2016) A modified closed-open approach as part of a graduated and integrative approach to rhinoplasty. Plastic and Reconstructive Surgery 4(9S): 242.

5. Kuduban O, Kuduban SD (2015) Early skin reaction of polydioxanone suture material following septorhinoplasty. The American journal of case reports 16: 276-278.

6. Alinasab B, Haraldsson PO (2016) Rapid resorbable sutures are a favourable alternative to non-resorbable sutures in closing transcolumellar incision in rhinoplasty. Aesthetic plastic surgery 40(4): 449-452.

7. Gurusamy KS, Toon CD, Allen VB, Davidson BR (2014) Continuous versus interrupted skin sutures for non-obstetric surgery. Cochrane Database of Systematic Reviews 14(2): CD010365.

8. Sajid MS, McFall MR, Whitehouse PA, Sains PS (2014) Systematic review of absorbable vs non-absorbable sutures used for the closure of surgical incisions. World journal of gastrointestinal surgery 6(12): 241-247.

9. Xu B, Xu B, Wang L, Chen C, Yilmaz TU, Zheng W, et al. (2016) Absorbable versus nonabsorbable sutures for skin closure: a meta-analysis of randomized controlled trials. Annals of plastic surgery 76(5): 598-606.

10. Beegun I, Saleh HA (2017) Advocating the use of absorbable sutures for columellar incisions following open rhinoplasty. Aesthetic plastic surgery 41(3): 754 .

11. Ashraf N, Foden N, D'souza A (2017) Closure of the trans-columellar incision in open septorhinoplasty in 100 patients: Use of an absorbable multifilament suture. Clinical Otolaryngology 42(5): 1085-1087.

12. Kilavuz AE, Bayram AA, Serin GM (2017) Comparison of absorbable and nonabsorbable sutures in columellar incision closure in rhinoplasty and their effects to postoperative scar. Facial Plastic Surgery. 33(6): 661-664. 


\section{ISSN: 2574-1241}

DOI: 10.26717/BJSTR.2019.21.003541

Moslem Armoeyan. Biomed J Sci \& Tech Res

(c) (P) This work is licensed under Creative

Submission Link: https://biomedres.us/submit-manuscript.php

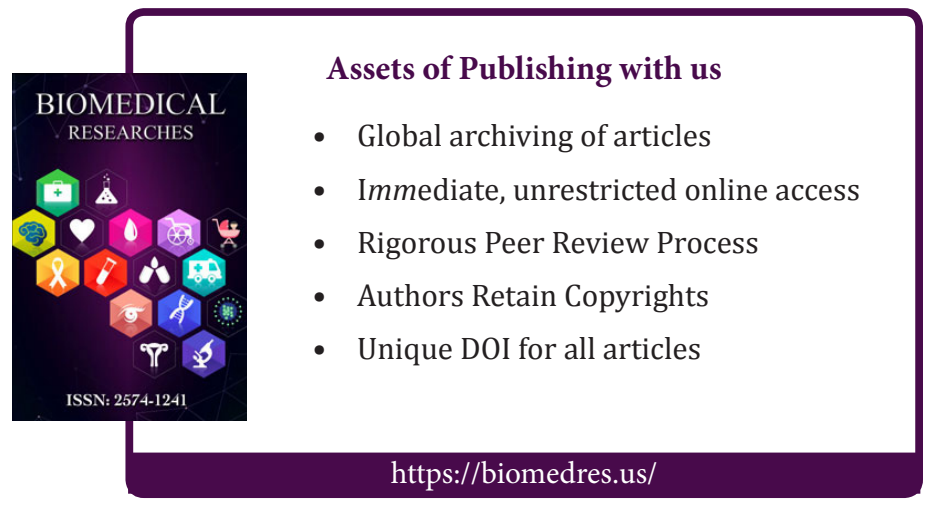

